\title{
Food insecurity, mental health and quality of life among people living with HIV commencing antiretroviral treatment in Ethiopia: a cross-sectional study
}

Markos Tesfaye ${ }^{1,2^{*}}$, Pernille Kaestel ${ }^{2}$, Mette Frahm Olsen ${ }^{2}$, Tsinuel Girma ${ }^{3}$, Daniel Yilma ${ }^{4}$, Alemseged Abdissa ${ }^{5}$, Christian Ritz ${ }^{2}$, Martin Prince ${ }^{6}$, Henrik Friis ${ }^{2}$ and Charlotte Hanlon ${ }^{6,7}$

\begin{abstract}
Background: Studies from high-income settings show that both food insecurity and common mental disorders (CMDs) are associated with lower quality of life among people living with HIV (PLHIV). However, there is limited research among PLHIV in sub-Saharan Africa. In this study we tested the hypothesis that food insecurity and CMDs would be associated with poorer quality of life of PLHIV in Ethiopia.

Methods: A cross-sectional study was carried out with 348 PLHIV who were initiating antiretroviral therapy recruited from two primary care centers and a tertiary Hospital in southwest Ethiopia. Food insecurity, CMD, and quality of life were measured using instruments adapted and validated in Ethiopia (Household Food Insecurity Access Scale, Kessler-6, and WHOQOL-HIV-BREF-ETH, respectively). Multiple linear regression analysis was used to identify factors associated with quality of life after adjusting for confounders.

Results: The prevalence of severe household food insecurity among PLHIV was $38.7 \%$. After adjusting for confounders, severe food insecurity ( $\beta=-3.24,95 \% \mathrm{Cl}:-6.19 ;-0.29)$ and higher levels of CMD symptoms ( $\beta=-1.72$ for each 1 point increase, $95 \% \mathrm{Cl}:-1.94 ;-1.49)$ were associated with lower quality of life. Other factors associated with lower quality of life were advanced HIV disease $(\beta=-3.80,95 \% \mathrm{Cl}:-6.18 ;-1.42)$, and being underweight $(\mathrm{BMI}=17.0-18.5 \mathrm{~kg} /$ $\left.\mathrm{m}^{2}\right)(\beta=-3.45,95 \% \mathrm{Cl}:-6.18 ;-0.71)$. Owning more household assets was associated with higher quality of life ( $\beta=0.99$ for owning one more asset, $95 \%$ Cl: 0.09; 1.89).
\end{abstract}

Conclusion: Poor mental health and food insecurity are associated with lower quality of life in PLHIV. There is a need for longitudinal studies to elucidate the pathways linking CMD, food insecurity and quality of life.

Keywords: Food insecurity, Common mental disorder, Quality of life, PLHIV, Africa

\section{Background}

Food insecurity, defined as "the limited or uncertain availability of nutritionally adequate and safe foods, or limited or uncertain ability to acquire acceptable foods in socially acceptable ways", is a global problem [1]. In 2009, the Ethiopian national nutrition report estimated that food insecurity affected $35 \%$ of the population [2].

\footnotetext{
* Correspondence: tesmarkos@yahoo.com

'Department of Psychiatry, College of Health Sciences, Jimma University, Jimma, Ethiopia

${ }^{2}$ Department of Nutrition, Exercise and Sports, Faculty of Science, University of Copenhagen, Copenhagen, Denmark

Full list of author information is available at the end of the article
}

The common mental disorders (CMD), depression and anxiety, are major contributors to the global burden of disease, with depression accounting for $9.6 \%$ of disability [3]. Both food insecurity and CMD symptoms have been found to be increased in people living with HIV (PLHIV) and associated with poorer HIV outcomes.

\section{Food insecurity in people living with HIV}

Prevalence estimates of all forms of food insecurity among PLHIV in sub-Saharan Africa (SSA) were $63 \%$ in Ethiopia [4], $75 \%$ in Uganda [5], $57 \%$ in the Democratic Republic of Congo [6], and $52 \%$ in Tanzania [7]. In line 
with this, severe food insecurity was common among PLHIV in SSA, ranging from 38 to $66 \%$ [5, 8]. A bidirectional relationship has been hypothesized between HIV and food insecurity, with food insecurity associated with increased risk of HIV infection, as well as HIV infection leading to food insecurity [9]. In addition to its nutritional consequences, food insecurity has been linked to poorer health outcomes, including incomplete viral suppression $[10,11]$, lower $C D 4^{+}$count $[11]$ and poor adherence to antiretroviral therapy (ART) $[6,12,13]$.

\section{CMD in people living with HIV}

Studies indicate that CMDs are common among PLHIV and lead to worse medical outcomes. A meta-analysis has shown PLHIV to have between two and five times higher prevalence of major depressive disorder than HIV negative controls [14]. In a systematic review, the average point prevalence of depressive disorders and anxiety disorders among PLHIV was found to be 41 and $34 \%$, respectively, in low and middle-income countries [15]. A study of CMDs among PLHIV receiving ongoing care in three public hospitals in Ethiopia found that approximately half of them had probable CMD [16]. That figure is much higher than the estimate for the general population in Ethiopia, which is 17 \% [17]. In PLHIV, CMDs, especially depression, are associated with a decrease in CD4 T-lymphocytes, increase in viral load and elevated risk of mortality [18] as well as lower quality of life [19, 20]. The existing evidence indicates an association between CMDs and non-adherence to ART [21]. On the other hand, CMDs have been associated with risky sexual behaviors that lead to HIV infection [22].

\section{Interrelationship between food insecurity, CMD and quality of life}

There appears to be complex interrelationships between food insecurity, CMDs and quality of life in PLHIV (Fig. 1). In a systematic review of studies from lowincome countries, food insecurity was found to be associated with CMDs [23]. In studies carried out in general population samples in Ethiopia, food insecurity has also been found to be associated with higher levels of CMD symptoms $[24,25]$. Similarly, studies done in PLHIV in low-income countries have found food insecurity was associated with CMDs, although only in women $[5,26]$. Evidence that food insecurity leads to higher CMDs rather than vice versa comes from a longitudinal study among poor communities within the US where food insecure PLHIV were found to become depressed [27].

While access to adequate food and nutrition in day-today life has been highlighted as an important dimension of quality of life among people living in low-income settings [28], studies have also found that food insecurity contributes to lower quality of life $[29,30]$. In SSA, there

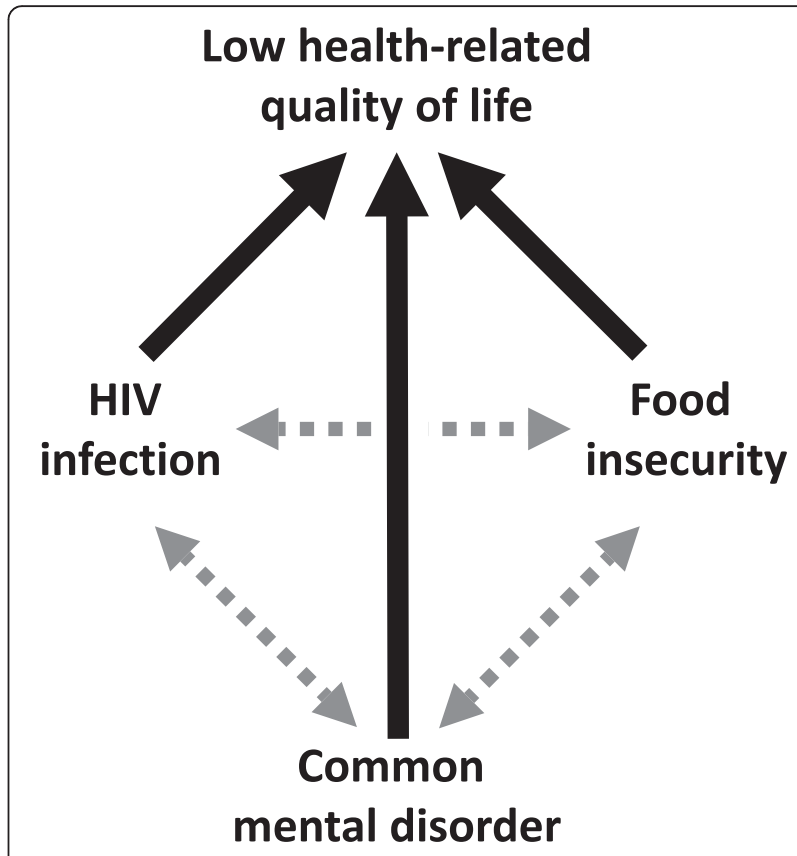

Fig. 1 The interrelationship among food insecurity, HIV, CMDs, and Quality of life

is a lack of data on the independent effect of food insecurity on the quality of life of PLHIV. A study on a community sample of ART-naïve PLHIV from Uganda found that severe food insecurity was associated with lower quality of life independent of dietary quality [8]. However, the study did not assess the nutritional and the mental health status of the PLHIV and their relative contribution to lower quality of life.

CMDs have also been linked to lower quality of life among PLHIV. Although studies from Ethiopia, and India reported CMDs to be associated with lower quality of life among PLHIV, these studies did not consider the potential confounding effect of food insecurity [19, 20, 31].

Improving quality of life is an important goal for HIV treatment programmes, but the existing evidence base is limited by the absence of studies examining the relative contributions food insecurity and CMD. In this study, we sought to investigate whether food insecurity and CMDs are associated with lowered quality of life in PLHIV, after adjusting for socio-economic status and malnutrition. The findings will help guide research and interventions aimed at improving the quality of life of PLHIV in low-income settings.

\section{Methods}

Study design and setting

A cross-sectional study was conducted in Jimma zone (sub-region), southwest Ethiopia between July 2010 and August 2012. The study was nested within a randomized controlled trial of a lipid-based nutrient supplement 
given to PLHIV who were initiating ART [32]. The sites included the ART clinics of Jimma University Specialized Hospital (JUSH), Jimma Health Centre and Agaro Health Centre.

\section{Participants and sampling}

A consecutive sample of 348 PLHIV who were eligible to start ART at the study sites were invited to take part in the study. Exclusion criteria for this study were age $<18$ years, pregnancy, lactation, diabetes mellitus and current use of nutritional supplements.

\section{Data collection procedures}

Data were collected by clinical nurses, who were trained on the data collection procedures. The clinicians working in the ART clinic referred all ART eligible adult PLHIV to the research team. The data were collected just before ART initiation. The clinical nurses provided information regarding the study and evaluated the eligibility of participants for the study. Eligible participants who gave written consent to participate in the study underwent interviews conducted by the clinical nurses. Weight and height were measured to compute body mass index (BMI). Blood samples were collected from the participants for laboratory investigations such as hemoglobin and $\mathrm{CD}_{4}$ cell count.

\section{Main outcome measure Quality of life}

The "bref" version of the World Health Organization Quality of Life -HIV module (WHOQOL-HIV) was adapted and validated for use among Ethiopian PLHIV in Amharic and Afaan Oromo languages. The original tool has been validated to ensure semantic, item and measurement equivalences, and construct validity was found. (Tesfaye M, Olsen MF, Medhin G, Friis H, Hanlon C, Holm L: Adaptation and validation of the short version WHOQOL-HIV in Ethiopia, submitted). The adapted instrument, namely WHOQOL-HIV-BREF-ETH, has 27items asking the respondents to rate the different aspects of their subjective experience of their living standards in the 2 weeks before the interview. The responses were scored from 1 to 5 . Lower scores indicate worse quality of life. The total scores on the WHOQOL-HIV-BREF$\mathrm{ETH}$ which included two general items and six domains were used in the multivariable regression analysis. The total quality of life scores could range from a minimum value of 26 and a maximum of 130.

\section{Main exposures}

\section{Food insecurity}

This was assessed using the nine item version of the Household Food Insecurity Access Scale (HFIAS) with questions asking whether the respondent has experienced any of the indicators of food insecurity in the previous 1 month period [33]. This scale has previously been validated in Ethiopia [34].

\section{Common mental disorders (CMD)}

The Kessler-6 scale (K6) [35], which is a shorter version of the Kessler-10 scale, was used to measure CMDs. K6 is composed of six questions asking the respondents how often they have experienced symptoms of CMDs in the previous 30 days. The responses are coded on a Likert-scale from zero indicating 'never' to 4 indicating 'all of the time'. The K6 has been validated for detection of CMDs in the Ethiopian setting [36].

\section{Potential confounders}

Socio-demographic characteristics: age, sex, and marital status of the participants were recorded on structured questionnaires.

Socio-economic characteristics: highest level of education achieved, occupation, assets owned, and floor material of the houses were recorded using a structured and pre-tested questionnaire which was developed by the investigators.

BMI: height (in centimeters) and weight (in kilograms) of the participants were measured using a stadiometer and calibrated weighing scales, respectively.

WHO stage: the severity of HIV disease was graded using the World Health Organization (WHO) clinical staging with stage I indicates asymptomatic HIV whereas stage IV indicates the advanced disease.

\section{Data management and analyses}

Data were double entered using EpiData version 3.1 (EpiData Association, Odense, Denmark) and analysed with STATA IC version 11 (StataCorp LP, College Station, TX). Data on quality of life were grouped into domains (physical, independence, psychological, social, environment, and spirituality), and the mean values for the domains were calculated as recommended by the WHOQOL-HIV Group [37]. Food security was categorized as follows: food secure if none of the items were endorsed, mild food insecurity if the respondent endorsed any of the items 1, 2, 3, and/or 4 but not the items 5 to 9 , 'moderate food insecurity' if the respondent has endorsed items 5 and/or 6 but not the items 7 to 9 , and 'severe food insecurity' the respondent has endorsed items 7, 8 and/or 9 as previously used by other investigators [25]. Mild food insecurity represented reduction in the quality of food while moderate and severe food insecurity represented quantitative reduction.

Background characteristics of the PLHIV were presented as means (SD) and percentages. Bivariate and multiple linear regression analyses were conducted to test the associations of CMD symptoms and food insecurity with 
the total scores on the WHOQOL-HIV-BREF-ETH among PLHIV. Each potential confounder, i.e. sociodemographic characteristics, education, marital status, WHO stage, and nutritional status, was added to the model sequentially. As the data was collected over a period of 2 years, the effect of season i.e. dry and rainy on the model fit was also analyzed. The variables were only included in the multiple linear regression if they were found to significantly improve the model fit using the likelihood ratio test. The association between food insecurity and CMD symptoms was tested using multiple linear regression.

\section{Results}

\section{Sample characteristics}

As reported previously [38], out of 453 PLHIV recruited, a total of 348 (76.8 \%) were enrolled. The mean age of the participants was $32.9( \pm 8.8)$ years. The majority $(66.7 \%)$ were women, and more than half $(52.9 \%)$ were either divorced or widowed. Moderate and severe food insecurity were both common with a prevalence of $67.2 \%$ (Table 1).

The mean hemoglobin (SD) of the PLHIV was 128 (20.2) $\mathrm{g} / \mathrm{L}$. The WHO clinical stage of the PLHIV showed that $29.2 \%$ (100) had stage I disease, $29.8 \%$ (102) had stage II, and $32.5 \%$ (111) had stage III, while only $8.5 \%$ (29) of the PLHIV had stage IV disease. The mean CD4 count was 187 (110) cells/uL, and $20.8 \%$ of the PLHIV had at least one opportunistic infection.

\section{Food insecurity, CMDs and total quality of life scores in PLHIV}

As shown in Table 2, increasing severity of food insecurity was associated with lower quality of life (test-for-trend, $p=$ 0.009). A higher level of CMD symptoms was associated with lower quality of life $(\beta=-1.72,95 \% \mathrm{CI}:-1.94 ;-1.49)$. Furthermore, having advanced HIV disease $(\beta=-3.80,95 \%$ CI: $-6.18 ;-1.42)$, and having mild malnutrition (BMI = $17.0-18.5 \mathrm{Kg} / \mathrm{m}^{2}$ ) were also associated with lower quality of life scores $(\beta=-3.45,95 \% \mathrm{CI}$ : $-6.18 ;-0.71)$. In the adjusted model, moderate to severely low BMI was not associated with lower quality of life $(\beta=-0.70,95 \% \mathrm{CI}$ : $-3.87 ; 2.46)$. However, the coefficients for mildly low BMI and that for moderate to severely low BMI were not significantly different from each other $(P=0.12)$. On the other hand, the number of household assets owned was positively associated with higher quality of life $(\beta=0.99,95 \% \mathrm{CI}$ : 0.09; $1.89)$. Season was not associated with quality of life scores.

\section{Food insecurity and CMDs}

As shown in Table 3, a higher burden of CMD symptoms was observed with increasing severity of food insecurity. Severe food insecurity ( $\beta=2.40,95 \% \mathrm{CI}: 1.05 ; 3.74)$ had a significantly stronger association with CMD symptoms than moderate food insecurity $(\beta=2.31,95 \% \mathrm{CI}$ : 0.92 ;
Table 1 Background characteristics of 348 adults with HIV

\begin{tabular}{|c|c|}
\hline & $N(\%)$ \\
\hline Age, mean (SD) & $32.9(8.8)$ \\
\hline \multicolumn{2}{|l|}{ Sex } \\
\hline Male & $116(33.3)$ \\
\hline Female & $232(66.7)$ \\
\hline \multicolumn{2}{|l|}{ Marital status } \\
\hline Married & $129(37.3)$ \\
\hline Divorced or widowed & $183(52.9)$ \\
\hline Never married & $32(9.3)$ \\
\hline \multicolumn{2}{|l|}{ Occupation } \\
\hline Employed & $78(22.4)$ \\
\hline Daily labour/local trade & $119(34.2)$ \\
\hline Housewife & $65(18.7)$ \\
\hline Unemployed & $42(12.1)$ \\
\hline Other & $44(12.6)$ \\
\hline \multicolumn{2}{|l|}{ Education } \\
\hline No formal education & $101(29.0)$ \\
\hline Primary & $179(50.3)$ \\
\hline Secondary and above & $72(20.7)$ \\
\hline \multicolumn{2}{|l|}{ Assets owned } \\
\hline$<2$ assets & $169(48.6)$ \\
\hline$\geq 2$ assets & $179(51.4)$ \\
\hline \multicolumn{2}{|l|}{ Floor material } \\
\hline Earth/sand/dung & $251(74.5)$ \\
\hline Tiles/cement/parquet & $86(25.5)$ \\
\hline \multicolumn{2}{|l|}{ Food insecurity } \\
\hline None & $45(13.1)$ \\
\hline Mild & $68(19.8)$ \\
\hline Moderate & $98(28.5)$ \\
\hline Severe & $133(38.7)$ \\
\hline \multicolumn{2}{|l|}{ Body mass index $\left[\mathrm{Kg} / \mathrm{m}^{2}\right]$} \\
\hline Severely low $(<16)$ & $30(8.7)$ \\
\hline Moderately low (16 - 17) & $32(9.2)$ \\
\hline Underweight (17 - 18.5) & $95(27.4)$ \\
\hline Normal (18.5 - 25) & $181(52.2)$ \\
\hline Overweight (>25) & $9(2.6)$ \\
\hline
\end{tabular}

3.71), $(p=0.001)$. Moreover, CMD symptoms were negatively associated with primary education $(\beta=-1.66,95 \%$ CI: $-2.99 ;-0.35)$, and positively associated with moderate and severe malnutrition i.e. BMI less than $17 \mathrm{~kg} / \mathrm{m}^{2}(\beta=$ 1.62, 95 \% CI: $0.16 ; 3.07)$ as well as with being widowed or divorced $(\beta=0.96,95 \%$ CI: $0.25 ; 2.18)$.

\section{Discussion}

This study found that two-thirds of PLHIV initiating ART lived in households affected by moderate to severe 
Table 2 Factors associated with total quality of life in a sample of 348 adults with HIV

\begin{tabular}{|c|c|c|}
\hline Characteristic & Unadjusted $\beta$ (95 \% Cl) & Adjusted $\beta(95 \% \mathrm{Cl})^{2}$ \\
\hline \multicolumn{3}{|l|}{ Sex } \\
\hline Male & Reference & Reference \\
\hline Female & $-1.35(-4.64 ; 1.94)$ & $-0.01(-2.84 ; 2.83)$ \\
\hline Age, years & $-0.05(-0.23 ; 0.12)$ & $-0.11(-0.25 ; 0.04)$ \\
\hline \multicolumn{3}{|l|}{ Marital status } \\
\hline Married & Reference & Reference \\
\hline Widowed/divorced & $-5.78(-9.06 ;-2.49)$ & $-0.57(-3.18 ; 2.04)$ \\
\hline Never married & $-4.21(-9.89 ; 1.46)$ & $-1.63(-5.95 ; 2.68)$ \\
\hline \multicolumn{3}{|l|}{ Educational level } \\
\hline No formal education & Reference & Reference \\
\hline Primary & $5.89(2.31 ; 9.47)$ & $1.00(-1.82 ; 3.82)$ \\
\hline Secondary and above & $6.95(2.50 ; 11.40)$ & $0.73(-2.98 ; 4.45)$ \\
\hline $\begin{array}{l}\text { Household assets } \\
\text { (out of } 7 \text { ) }\end{array}$ & $2.01(0.94 ; 3.07)$ & $0.99(0.09 ; 1.89)$ \\
\hline \multicolumn{3}{|l|}{ Food insecurity } \\
\hline None or Mild & Reference & Reference $^{\mathrm{b}}$ \\
\hline Moderate & $-7.62(-11.45 ;-3.78)$ & $-2.52(-5.55 ; 0.51)$ \\
\hline Severe & $-10.06(-13.61 ;-6.51)$ & $-3.24(-6.19 ;-0.29)$ \\
\hline \multicolumn{3}{|l|}{ Body mass index $\left[\mathrm{Kg} / \mathrm{m}^{2}\right]$} \\
\hline $\begin{array}{l}\text { Normal or overweight } \\
(\geq 18.5)\end{array}$ & Reference & Reference \\
\hline Mildly low (17-18.5) & $-5.46(-9.07 ;-1.85)$ & $-3.45(-6.18 ;-0.71)$ \\
\hline $\begin{array}{l}\text { Moderate to severely } \\
\text { low }(<17.0)\end{array}$ & $-4.69(-8.88 ;-0.50)$ & $-0.70(-3.87 ; 2.46)$ \\
\hline CMD scores & $-1.84(-2.06 ;-1.62)$ & $-1.72(-1.94 ;-1.49)$ \\
\hline \multicolumn{3}{|l|}{ WHO stage of HIV } \\
\hline Stage | \& || & Reference & Reference \\
\hline Stage III \& IV & $-5.26(-8.42 ;-2.10)$ & $-3.80(-6.18 ;-1.42)$ \\
\hline \multicolumn{3}{|l|}{ Season } \\
\hline Dry & Reference & \\
\hline Rainy & $-0.32(-3.54 ; 2.91)$ & - \\
\hline
\end{tabular}

${ }^{a}$ Adjusted for age, sex, marital status, education, household assets, food insecurity, BMI, WHO stage, and CMD scores

${ }^{\mathrm{b}}$ Test for trend was significant $(p=0.009)$

food insecurity. Food insecurity and higher levels of CMD symptoms were associated with lower quality of life. Also, advanced HIV disease and lower BMI were associated with lower quality of life. PLHIV who owned household assets appear to have better quality of life. However, age, sex, and marital status were not found to be associated with quality of life among PLHIV. Furthermore, food insecurity was associated with a high burden of CMD symptoms.

The proportion of PLHIV who reported moderate and severe household food insecurity is comparable to a previous report from the same setting [4] and to other reports from SSA [6]. Household food insecurity among
Table 3 Factors associated with common mental disorders in a sample of 348 adults with HIV

\begin{tabular}{|c|c|c|}
\hline Characteristic & Unadjusted $\beta$ (95 \% Cl) & Adjusted $\beta(95 \% \mathrm{Cl})^{\mathrm{a}}$ \\
\hline \multicolumn{3}{|l|}{ Sex } \\
\hline Male & Reference & Reference \\
\hline Female & $1.44(0.28 ; 2.61)$ & $0.85(-0.49 ; 2.18)$ \\
\hline Age, years & $-0.03(-0.09 ; 0.03)$ & $-0.02(-0.09 ; 0.05)$ \\
\hline \multicolumn{3}{|l|}{ Marital status } \\
\hline Married & Reference & Reference \\
\hline Widowed/divorced & $1.86(0.69 ; 3.04)$ & $0.96(0.25 ; 2.18)$ \\
\hline Never married & $0.62(-1.39 ; 2.63)$ & $-0.40(-2.44 ; 1.65)$ \\
\hline \multicolumn{3}{|l|}{ Educational level } \\
\hline No formal education & Reference & Reference \\
\hline Primary & $-2.26(-3.54 ;-0.99)$ & $-1.66(-2.99 ;-0.35)$ \\
\hline Secondary and above & $-2.09(-3.66 ;-0.52)$ & $-0.96(-2.60 ; 0.69)$ \\
\hline $\begin{array}{l}\text { Household assets } \\
\text { (out of } 7 \text { ) }\end{array}$ & $-0.34(-0.73 ; 0.04)$ & - \\
\hline \multicolumn{3}{|l|}{ Food insecurity } \\
\hline None or Mild & Reference & Reference \\
\hline Moderate & $2.52(1.13 ; 3.91)$ & $2.31(0.92 ; 3.71)$ \\
\hline Severe & $2.89(1.61 ; 4.18)$ & $2.40(1.05 ; 3.74)$ \\
\hline \multicolumn{3}{|l|}{ Body mass index $\left[\mathrm{Kg} / \mathrm{m}^{2}\right]$} \\
\hline $\begin{array}{l}\text { Normal or overweight } \\
(\geq 18.5)\end{array}$ & Reference & Reference \\
\hline Mildly low (17-18.5) & $0.90(-0.40 ; 2.20)$ & $0.99(-0.28 ; 2.26)$ \\
\hline $\begin{array}{l}\text { Moderate to severely } \\
\text { Iow }(<17.0)\end{array}$ & $1.73(0.22 ; 3.24)$ & $1.62(0.16 ; 3.07)$ \\
\hline \multicolumn{3}{|l|}{ WHO stage of HIV } \\
\hline Stage | \& || & Reference & \\
\hline Stage III \& IV & $0.33(-0.81 ; 1.47)$ & - \\
\hline
\end{tabular}

${ }^{a}$ Adjusted for age, sex, marital status, education, food insecurity, and BMI

PLHIV in our sample was nearly double that of the general population in Ethiopia [2]. This suggests that PLHIV are vulnerable to food insecurity. Accordingly, a study done in Canada has found that food insecurity was five times more prevalent among PLHIV than the general population [39]. It has been indicated that PLHIV in particular could suffer from food insecurity resulting from the decreased productivity, and increased healthcare expenditures [9].

In line with previous evidence $[8,29]$, the findings provide further evidence on the association of food insecurity with quality of life. In low-income settings, the significance of access to adequate food and nutrition for a person's quality of life has been highlighted previously [28]. It is likely that individuals from food insecure households also experience general deprivation and poverty. This is supported by our findings that ownership of household assets being associated with higher quality of life. Thus, food support programs as well as financial 
support might lead to improved quality of life among PLHIV. The apparent attenuation of the association between lower quality of life and moderately and severely low BMI after adjusting for confounders might be due to underpowered sample size. Thus, PLHIV who exhibit undernutrition may have lower quality of life as reported by another study from India [40].

Previous studies have found CMDs to be associated with poor quality of life among PLHIV [19, 20, 31]. Our data also suggest that CMDs may have interaction with food insecurity, although the direction of association cannot be determined in this cross-sectional study. Prospective studies are required in order to further elucidate the direction of association between CMDs and quality of life. Policies and program guidelines aimed at improving the quality of life of PLHIV who are starting ART treatment need to address the mental healthcare needs of this population in addition to tackling food insecurity.

People with chronic illnesses generally report poorer quality of life than their healthy counterparts. Our finding on the association between stage of HIV disease and quality of life is consistent with other studies that have demonstrated that PLHIV who are symptomatic have poorer quality of life than healthy individuals and even asymptomatic PLHIV [40]. It is possible that the quality of life of PLHIV who are effectively treated with ART may not be different from that of people who are HIV negative. Indeed, a recent study from Uganda has found that PLHIV on ART had better quality of life than a comparable community sample [41]. Accordingly, it may be the general health condition, and the fear and the stigma of the PLHIV, which may partly resolve with effective treatment with ART, rather than HIV serostatus per se that accounted for the poorer quality of life in this study.

Food insecurity has been linked to poorer mental health in a systematic review of studies from lowincome countries [23] as well as in community studies from high-income countries [42-44]. Similarly, studies on PLHIV have also found association between food insecurity and poorer mental health $[41,45,46]$. The observed relationship between more severe food insecurity and poorer mental health in our study supports a causal association although this cannot be confirmed due to the cross-sectional nature of the analysis. In Ethiopia, adults suffering from depression have been found to experience functional disability [47] and hence loss of financial resources. The available evidence supports that treatment of CMDs generally results in improved income of the patients and their families [48]. It is possible that the household food insecurity in our study sample reflected the extreme levels of poverty which may have acted as a chronic stressor leading to a high burden of CMD symptoms. By contrast, the number of household assets owned, a measure of socio-economic status, was not associated with mental health. The absence of assets is not an immediate stressor and thus, may not be expected to have an association with mental health status, whereas food insecurity represents acute poverty and is felt immediately as a stressor.

In addition to food insecurity, low level of education was one of the measures of poverty that was found to be consistently associated with CMDs in a systematic review [49]. Our data also supports the previous findings from low-income settings. The attenuation of the association between a secondary and higher education and CMD symptoms might be due to the smaller sample size of that particular group. However, the exact mechanism as to how lower education might lead to higher burden of CMD symptoms needs further research.

The link between BMI and poor mental health is inconsistent in the literature. Studies have found CMDs to be associated with obesity [49-52], and low BMI [53, 54]. Other studies did not find any association between BMI and CMDs [55, 56]. The observed association between low BMI and CMD symptoms indicates that undernourished PLHIV have increased mental healthcare needs in addition to nutritional and medical interventions.

Our findings may not be generalized to all PLHIV as participants were recruited from health facilities and they represent a segment of the community with better access to health services. The PLHIV who did not participate may be systematically different from those who participated in this study, and the results might have been biased as a result. The assessment of CMDs was not based on gold standard clinical interview but rather using the Kessler scale which is a screening tool. Nevertheless, evidence supports that persons with greater number of CMD symptoms have higher likelihood of being a case of CMD, and experiencing disability. Both food insecurity and CMDs have previously been linked to poor physical health status. Social support which might buffer the association between food security, and mental health and quality of life could have confounded the results.

\section{Conclusion}

Poor mental health and food insecurity are associated with lower quality of life in PLHIV. There is a need for longitudinal studies to elucidate the pathways linking CMD, food insecurity and quality of life.

\section{Ethics approval and consent to participate}

The study was approved by the Ethiopian National Health Research Ethics Review Committee and the Research Ethical Review Committee of Jimma University. Written informed consent was sought from participants of the study. 


\section{Availability of data and materials Additional data are available on request from the corre- sponding author.}

\section{Abbreviations}

ART: antiretroviral therapy; BMI: body mass index; CMD: common mental disorder; HFIAS: household food insecurity access scale; JUSH: Jimma University Specialized Hospital; K6: Kessler-6 scale; PLHIV: people living with HIV; SSA: SubSaharan Africa; WHO: World Health Organization; WHOQOL-HIV: World Health Organization quality of life $-\mathrm{HIV}$ module.

\section{Competing interests}

The authors declare that they have no competing interests.

\section{Authors' contribution}

MT, $\mathrm{CH}$ and HF conceived the study. MT, PK, HF, CH, MFO, and TG designed the study. MT, TG, PK, DY and AA contributed to data acquisition. MT, CH, MP, PK, HF and CR contributed to the analysis of data. All authors contributed to the data interpretation, and reviewed the manuscript. All authors read and approved the final manuscript.

\section{Acknowledgments}

We thank the study participants for their cooperation. We are grateful to Jimma University Specialized Hospital - HIV clinic staff and the JUCAN staff for their support during data acquisition.

\section{Funding}

The study was funded by University of Copenhagen through the Jimma University and University of Copenhagen Alliance in Nutrition (JUCAN) project. The funding body did not have role in the design of the study and collection, analysis, and interpretation of data and in writing the manuscript.

\section{Author details}

${ }^{1}$ Department of Psychiatry, College of Health Sciences, Jimma University, Jimma, Ethiopia. ${ }^{2}$ Department of Nutrition, Exercise and Sports, Faculty of Science, University of Copenhagen, Copenhagen, Denmark. ${ }^{3}$ Department of Pediatrics and Child Health, College of Health Sciences, Jimma University, Jimma, Ethiopia. ${ }^{4}$ Department of Internal Medicine, College of Health Sciences, Jimma University, Jimma, Ethiopia. ${ }^{5}$ Department of Medical Laboratory Sciences \& Pathology, College of Health Sciences, Jimma University, Jimma, Ethiopia. ${ }^{6}$ Centre for Global Mental Health, Institute of Psychiatry, King's College London, London, UK. ${ }^{7}$ Department of Psychiatry, School of Medicine, College of Health Sciences, Addis Ababa University, Addis Ababa, Ethiopia.

Received: 22 August 2015 Accepted: 29 February 2016 Published online: 03 March 2016

\section{References}

1. Food and Agriculture Organization: The State of Food Insecurity in the World. Rome: FAO, United Nations; 2004.

2. Ethiopian Health Nutrition Research Institute (EHNRI). Nutrition baseline survey report for the national nutrition program of Ethiopia. Addis Ababa, Ethiopia: EHNRI; 2009.

3. Ferrari AJ, Charlson FJ, Norman RE, Patten SB, Freedman G, Murray CJL, et al. Burden of depressive disorders by country, Sex, Age, and year: findings from the global burden of disease study 2010. PLoS Med. 2013;10:e1001547.

4. Tiyou A, Belachew T, Alemseged F, Biadgilign S. Food insecurity and associated factors among HIV-infected individuals receiving highly active antiretroviral therapy in Jimma zone Southwest Ethiopia. Nutr J. 2012;11:51.

5. Tsai AC, Bangsberg DR, Frongillo EA, Hunt PW, Muzoora C, Martin JN, et al. Food insecurity, depression and the modifying role of social support among people living with HIV/AIDS in rural Uganda. Soc Sci Med. 2012;74:2012-9.

6. Musumari PM, Wouters E, Kayembe PK, Kiumbu Nzita M, Mbikayi SM, Suguimoto SP, et al. Food insecurity is associated with increased risk of non-adherence to antiretroviral therapy among HIV-infected adults in the Democratic Republic of Congo: a cross-sectional study. PLoS One. 2014:9:e85327.

7. Semali IA, Edwin T, Mboera LEG. Food insecurity and coping strategies among people living with HIV in Dar es Salaam, Tanzania. Tanzan J Health Res. 2011;13:86-94.
8. Palermo T, Rawat R, Weiser SD, Kadiyala S. Food access and diet quality are associated with quality of life outcomes among HIV-infected individuals in Uganda. PLoS One. 2013;8:e62353.

9. Weiser SD, Young SL, Cohen CR, Kushel MB, Tsai AC, Tien PC, et al. Conceptual framework for understanding the bidirectional links between food insecurity and HIV/AIDS. Am J Clin Nutr. 2011:94:1729S-39S.

10. Kalichman SC, Cherry C, Amaral C, White D, Kalichman MO, Pope H, et al. Health and treatment implications of food insufficiency among people living with HIV/AIDS, Atlanta, Georgia. J Urban Health Bull N Y Acad Med. 2010;87:631-41.

11. Weiser SD, Frongillo EA, Ragland K, Hogg RS, Riley ED, Bangsberg DR. Food insecurity is associated with incomplete HIV RNA suppression among homeless and marginally housed HIV-infected individuals in San Francisco. J Gen Intern Med. 2009;24:14-20

12. Au JT, Kayitenkore K, Shutes E, Karita E, Peters PJ, Tichacek A, et al. Access to adequate nutrition is a major potential obstacle to antiretroviral adherence among HIV-infected individuals in Rwanda. AIDS Lond Engl. 2006;20:2116-8.

13. Kalichman SC, Grebler T, Amaral CM, McKerney M, White D, Kalichman MO, et al. Food insecurity and antiretroviral adherence among HIV positive adults who drink alcohol. J Behav Med. 2013;37:1009-18.

14. Ciesla J, Roberts J. Meta-analysis of the relationship between HIV infection and risk for depressive disorders. Am J Psychiatry. 2001;158:725-30.

15. Lowther K, Selman L, Harding R, Higginson IJ. Experience of persistent psychological symptoms and perceived stigma among people with HIV on antiretroviral therapy (ART): a systematic review. Int J Nurs Stud. 2014;51:1171-89.

16. Deribew A, Tesfaye M, Hailmichael Y, Apers L, Abebe G, Duchateau L, et al. Common mental disorders in TB/HIV co-infected patients in Ethiopia. BMC Infect Dis. 2010;10:201

17. Alem A, Kebede D, Woldesemiat G, Jacobsson L, Kullgren G. The prevalence and socio-demographic correlates of mental distress in Butajira, Ethiopia. Acta Psychiatr Scand Suppl. 1999:397:48-55.

18. Leserman J. Role of depression, stress, and trauma in HIV disease progression. Psychosom Med. 2008;70:539-45.

19. Deribew A, Deribe K, Reda AA, Tesfaye M, Hailmichael Y, Maja T, et al. Change in quality of life: a follow up study among patients with HIV infection with and without TB in Ethiopia. BMC Public Health. 2013;13:408.

20. Deribew A, Tesfaye M, Hailmichael Y, Negussu N, Daba S, Wogi A, et al. Tuberculosis and HIV co-infection: its impact on quality of life. Health Qual Life Outcomes. 2009;7:105.

21. Horberg MA, Silverberg MJ, Hurley LB, Towner WJ, Klein DB, Bersoff-Matcha $S$, et al. Effects of depression and selective serotonin reuptake inhibitor use on adherence to highly active antiretroviral therapy and on clinical outcomes in HIV-infected patients. J Acquir Immune Defic Syndr. 2008;47:384-90.

22. Nduna M, Jewkes RK, Dunkle KL, Shai NPJ, Colman I. Associations between depressive symptoms, sexual behaviour and relationship characteristics: a prospective cohort study of young women and men in the Eastern Cape, South Africa. J Int AIDS Soc. 2010;13:44.

23. Weaver $L$, Hadley C. Moving beyond hunger and nutrition: a systematic review of the evidence linking food insecurity and mental health in developing countries. Ecol Food Nutr. 2009:48:263-84.

24. Hadley C, Tegegn A, Tessema F, Cowan JA, Asefa M, Galea S. Food insecurity, stressful life events and symptoms of anxiety and depression in east Africa: evidence from the Gilgel Gibe growth and development study. J Epidemiol Community Health. 2008:62:980-6.

25. Maes KC, Hadley C, Tesfaye F, Shifferaw S. Food insecurity and mental health: surprising trends among community health volunteers in Addis Ababa, Ethiopia during the 2008 food crisis. Soc Sci Med. 2010:70:1450-7

26. Heylen E, Panicker ST, Chandy S, Steward WT, Ekstrand ML. Food insecurity and its relation to psychological well-being among south Indian people living with HIV. AIDS Behav. 2015;19:1548-58.

27. Palar K, Kushel M, Frongillo EA, Riley ED, Grede N, Bangsberg D, et al. Food insecurity is longitudinally associated with depressive symptoms among homeless and marginally-housed individuals living with HIV. AIDS Behav. 2015:19:1527-34.

28. Skevington SM. Conceptualising dimensions of quality of life in poverty. J Community Appl Soc Psychol. 2009;19:33-50.

29. Sharkey JR, Johnson CM, Dean WR. Relationship of household food insecurity to health-related quality of life in a large sample of rural and urban women. Women Health. 2011:51:442-60. 
30. Vailas LI, Nitzke SA, Becker M, Gast J. Risk indicators for malnutrition are associated inversely with quality of life for participants in meal programs for older adults. J Am Diet Assoc. 1998;98:548-53.

31. Peter E, Kamath R, Andrews T, Hegde BM. Psychosocial determinants of health-related quality of life of people living with HIV/AIDS on antiretroviral therapy at udupi district, southern India. Int J Prev Med. 2014;5:203-9.

32. Olsen MF, Abdissa A, Kæstel P, Tesfaye M, Yilma D, Girma T, et al. Effects of nutritional supplementation for HIV patients starting antiretroviral treatment: randomised controlled trial in Ethiopia. BMJ. 2014;348:93187.

33. Coates J, Swindale A, Bilinsky P. Household food insecurity access scale (HFIAS) for measurement of food access: indicator guide (v.3). Washington, D.C: Food and Nutrition Technical Assistance Project, Academy for Educational Development; 2007.

34. Maes KC, Hadley C, Tesfaye F, Shifferaw S, Tesfaye YA. Food insecurity among volunteer AIDS caregivers in addis Ababa, Ethiopia was highly prevalent but buffered from the 2008 food crisis. J Nutr. 2009;139:1758-64

35. Kessler RC, Andrews G, Colpe L, Hiripi E, Mroczek DK, Normand SLT, et al. Short screening scales to monitor population prevalences and trends in non-specific psychological distress. Psychol Med. 2002;32:959-76.

36. Tesfaye M, Hanlon C, Wondimagegn D, Alem A. Detecting postnatal common mental disorders in Addis Ababa, Ethiopia: validation of the Edinburgh postnatal depression scale and Kessler scales. J Affect Disord. 2010;122:102-8.

37. World Health Organization. WHOQOL-HIV instrument, users manual. Geneva: $\mathrm{WHO} ; 2002$.

38. Olsen MF, Kæstel P, Tesfaye M, Abdissa A, Yilma D, Girma T, et al. Physical activity and capacity at initiation of antiretroviral treatment in HIV patients in Ethiopia. Epidemiol Infect. 2015;143:1048-58.

39. Normén L, Chan K, Braitstein P, Anema A, Bondy G, Montaner JSG, et al. Food insecurity and hunger are prevalent among HIV-positive individuals in British Columbia, Canada. J Nutr. 2005;135:820-5.

40. Anand D, Puri S, Mathew M. Assessment of quality of life of HIV-positive people receiving ART: an Indian perspective. Indian J Community Med. 2012;37:165-9

41. O'Connell K, Skevington S, Saxena S, WHOQOL HIV. Group: preliminary development of the world health Organsiation's quality of life HIV instrument (WHOQOL-HIV): analysis of the pilot version. Soc Sci Med. 2003;57:1259-75.

42. Martin F, Russell S, Seeley J. Higher quality of life and lower depression for people on ART in Uganda as compared to a community control group. PLoS One. 2014;9:e105154.

43. Willows N, Veugelers P, Raine K, Kuhle S. Associations between household food insecurity and health outcomes in the Aboriginal population (excluding reserves). Health Rep. 2011;22:15-20.

44. Liu Y, Njai RS, Greenlund KJ, Chapman DP, Croft JB. Relationships between housing and food insecurity, frequent mental distress, and insufficient sleep among adults in 12 US States, 2009. Prev Chronic Dis. 2014;11:E37.

45. Carter KN, Kruse K, Blakely T, Collings S. The association of food security with psychological distress in New Zealand and any gender differences. Soc Sci Med. 2011;72:1463-71.

46. Weiser SD, Bangsberg DR, Kegeles S, Ragland K, Kushel MB, Frongillo EA. Food insecurity among homeless and marginally housed individuals living with HIV/AIDS in San Francisco. AIDS Behav. 2009;13:841-8.

47. Vogenthaler NS, Hadley C, Rodriguez AE, Valverde EE, del Rio C, Metsch LR. Depressive symptoms and food insufficiency among HIV-infected crack users in Atlanta and Miami. AIDS Behav. 2011;15:1520-6.

48. Mogga S, Prince M, Alem A, Kebede D, Stewart R, Glozier N, et al. Outcome of major depression in Ethiopia: population-based study. Br J Psychiatry J Ment Sci. 2006;189:241-6.

49. Lund C, De Silva M, Plagerson S, Cooper S, Chisholm D, Das J, et al. Poverty and mental disorders: breaking the cycle in low-income and middle-income countries. Lancet. 2011;378:1502-14.

50. Lund C, Breen A, Flisher AJ, Kakuma R, Corrigall J, Joska JA, et al. Poverty and common mental disorders in low and middle income countries: A systematic review. Soc Sci Med. 2010;71:517-28.

51. Kivimäki M, Jokela M, Hamer M, Geddes J, Ebmeier K, Kumari M, et al. Examining overweight and obesity as risk factors for common mental disorders using fat mass and obesity-associated (FTO) genotype-instrumented analysis: The Whitehall II Study, 1985-2004. Am J Epidemiol. 2011;173:421-9.

52. Scott KM, Bruffaerts R, Simon GE, Alonso J, Angermeyer M, de Girolamo G, et al. Obesity and mental disorders in the general population: results from the world mental health surveys. Int J Obes. 2008;32:192-200.
53. Brown WJ, Dobson AJ, Mishra G. What is a healthy weight for middle aged women? Int J Obes. 1998:22:520-8.

54. Kim KW, Kim SH, Shin JH, Choi BY, Nam JH, Park S-C. Psychosocial, physical, and autonomic correlates of depression in korean adults: results from a county-based depression screening study. Psychiatry Investig. 2014;11:402-11.

55. Borges G, Benjet C, Medina-Mora ME, Miller M. Body mass index and its relationship to mental disorders in the Mexican adolescent mental health survey. Salud Pública México. 2010;52:103-10.

56. de Paffer AT, da Ferreira HS, Cabral Júnior CR, de Miranda CT. Prevalence of common mental disorders in mothers in the semiarid region of Alagoas and its relationship with nutritional status. São Paulo Med J Rev Paul Med. 2012;130:84-91.

\section{Submit your next manuscript to BioMed Central and we will help you at every step:}

- We accept pre-submission inquiries

- Our selector tool helps you to find the most relevant journal

- We provide round the clock customer support

- Convenient online submission

- Thorough peer review

- Inclusion in PubMed and all major indexing services

- Maximum visibility for your research

Submit your manuscript at www.biomedcentral.com/submit
) Biomed Central 